\title{
The effects of combined therapy of myo-inositol and D-chiro inositol in reduction of the individual components of metabolic syndrome in overweight PCOS patients compared to myo-inositol supplementation alone: a prospective randomised controlled trial
}

\author{
Manideepa Pande $^{1}$, Ashish Seal ${ }^{1 *}$, Sukanta Mishra ${ }^{1}$, Arup Dasgupta ${ }^{2}$, \\ Mousumi Sengupta ${ }^{3}$, Rinini Dastider ${ }^{4}$
}

\begin{abstract}
${ }^{1}$ Department of Obstetrics and Gynecology, Vivekananda Institute of Medical Sciences, Kolkata, West Bengal, India ${ }^{2}$ Department of Anaesthesiology, ICARE Institute of Medical Sciences and Research, Banbishnupur, Purba Medinipur, Haldia, West Bengal, India ${ }^{3}$ Department of Radiology, Vivekananda Institute of Medical Sciences, Kolkata, West Bengal, India ${ }^{4}$ Department of Biochemistry, Vivekananda Institute of Medical Sciences, Kolkata, West Bengal 700026, India
\end{abstract}

Received: 17 April 2017

Accepted: 18 May 2017

\section{*Correspondence:}

Dr. Ashish Seal,

E-mail: aseal@rediffmail.com

Copyright: $(\odot$ the author(s), publisher and licensee Medip Academy. This is an open-access article distributed under the terms of the Creative Commons Attribution Non-Commercial License, which permits unrestricted non-commercial use, distribution, and reproduction in any medium, provided the original work is properly cited.

\begin{abstract}
Background: Polycystic ovarian syndrome (PCOS) is one of the most common endocrine disorder affecting five to ten percent women of reproductive age group. Variability of signs and symptoms along with metabolic syndrome as one of the long term complications make it worthy of early diagnosis and treatment. Medical management of PCOS is aimed at the treatment of metabolic derangements, anovulation, hirsutism, and menstrual irregularities.

Methods: 140 patients, using inclusion and exclusion criteria, were selected and randomly divided into two groups (seventy in each) and age, BMI, waist hip ratio, blood pressure (systolic, diastolic), serum fasting insulin, fasting blood sugar, total cholesterol, HDL, LDL, triglycerides were measured. Study group were given \{Myo-inositol (550 $\mathrm{mg})+$ D-chiro-inositol $(13.8 \mathrm{mg})\}$ (MI+DCI) twice daily and the control group were given Myo-inositol (1 gm) (MI) twice daily for six months. Same variables were measured at the end of three and six months and compared with repeated measurement ANOVA using SPSS (version 20).

Results: Comparison between these two groups before study was non-contributory. Combined drug therapy has provided statistically significant decrease in BMI, W:H ratio, Diastolic BP, Fasting blood sugar at the end of both 3rd and 6th month but in case of LDL it was at the end of 3 months. Combined drug therapy also increased the HDL level significantly in both the occasions.

Conclusions: Combined medical therapy by (MI+DCI) is very much helpful in reducing the metabolic complications of PCOS without any major side effects.
\end{abstract}

Keywords: Anovulation, D-chiro-inositol, Hirsutism, Myo-inositol, PCOS

\section{INTRODUCTION}

As the name suggests PCOS is a syndrome characterized by variable gynaecological and systemic signs and symptoms in association with cystic changes in ovary.
The signs and symptoms and their prevalence in PCOS are variable to a large extent and in one study ${ }^{(1)}$ it was found to be as following: infertility $40 \%$, hyperandrogenism $70 \%$, amenorrhoea $50 \%$, obesity 60 $80 \%$, abnormal uterine bleeding $30 \%$ and abnormal menstruation 20\%. ${ }^{1}$ A severe form of PCOS 
characterized by hyper-androgenism, insulin resistance and acanthosis nigricans is commonly referred as a popular acronym HAIR-AN Syndrome. ${ }^{2}$ It is the the most common cause of female infertility which is caused by a combination of hyperandrogenism, chronic anovulation and irregular menstrual cycle. ${ }^{3-5}$ Several patients affected by PCOS are also affected by insulin resistance $( \pm)$ signs of diabetes hyperinsulinemia. ${ }^{6-8}$ PCOS-induced insulin resistance determines a higher risk for the development of type 2 diabetes75, hypertension and dyslipidemia, all elements of the metabolic syndrome. ${ }^{2,9}$

\section{Diagnosis of PCOS}

Rotterdam Criteria May 2003 for the diagnosis of PCOS Any two of the following three features Oligo- or anovulation, clinical and/or biochemical signs of hyperandrogenism, polycystic ovaries. ${ }^{2}$

Modified definition of the WHO criteria for Metabolic Syndrome ${ }^{10}$

- Hyperinsulinemia (the upper fourth of the fasting insulin level among nondiabetic subjects) or hyperglycemia (fasting glucose $\geq 110 \mathrm{mg} / \mathrm{dl}$ ),

- In addition to at least two of the following: a) waist girth $\geq 94 \mathrm{~cm}$, b) dyslipidemia (triglycerides $\geq 150$ $\mathrm{mg} / \mathrm{dl}$ or HDL cholesterol $<40 \mathrm{mg} / \mathrm{dl}$ ), c) BP $\geq 140 / 90$ $\mathrm{mmHg}$ or taking BP medication.

Inositol (myo-inositol, D-chiro-inositol etc), a six-carbon polyol which has been characterized as an insulin sensitizer; in-deed, inositolphosphoglycan (IPG) mediators play a key-role in multiple cellular processes that control glucose metabolism and inositol is integral to properly functioning insulin receptors. Thus, a defect in tissue availability or altered metabolism of inositol, as in PCOS women, is a key factor in insulin resistance. ${ }^{11}$ Different studies have proved the efficacy of myoinositol in controlling the metabolic components of PCOS. Here we have compared the effects of (D-chiroinositol + myo-inositol) combined therapy vs myoinositol therapy alone in controlling the components of metabolic syndrome.

Aims and objective of present study were to compare the effects between (myo-inositol+D-chiro-inositol) and myo-inositol monotherapy in controlling individual components of metabolic syndrome and to evaluate the complications and side effects of the two drugs.

\section{METHODS}

Double blinded (subject/patient and outcome assessor) Randomized controlled trial with parallel group design. Considering at least one overweight PCOS women attending OPD clinic per day and giving consent to participate in the study, the study period would be till we complete our required number of sample size (upto a maximum period of 18 months-March2015 to September
2016). All overweight (BMI>27) PCOS women attending the OPD of Obstetrics and Gynaecology at VIMS, Kolkata. A total of number of 140 patients will be included in the study (70 patients in each group).

\section{Inclusion criteria}

For each group:

- Overweight (BMI>27) women satisfying Rotterdam criteria for diagnosis of PCOS.

- No other known causes of infertility

- No known metabolic disorder.

\section{Exclusion criteria}

- Women less than 18 years or more than 41 years old

- Patients on hormonal medication

- Known diabetic/hypertensive patient

- Known alcoholic or smoker.

Patients selected using inclusion and exclusion criteria will be randomized using computer generated randomization sequence into two groups (70 in each group). Pre-intervention tests are done for all the parameters and compared. One group has received myoinositol (1 gm BD) and another group has received [myoinositol (550mg) and D-chiro-inositol (13.8mg)] (1 tab BD) for 3 months. All the parameters are tested again and compared to test the significance. The same drug therapy to continue for the same group of patients for next 3 months. And at the end of 6 months all the parameters are measured and compared using appropriate statistical test. The protocol and both the patient information sheet and the consent form were submitted to the Institutional Ethics Committee of VIMS, Kolkata.

\section{Statistical analysis}

All the data collected are compiled in Microsoft excel sheet and have been analyzed using statistical software Statistical Package for the Social Sciences (SPSS Version 20) as per nature of the data with appropriate statistical tests. Analysis will be two tailed and $p<0.05$ has been considered as statistically significant.

\section{RESULTS}

Continuous variables like Age, BMI, Waist Hip Ratio, Systolic Blood Pressure, Diastolic Blood Pressure, Serum Fasting Insulin, Fasting Blood Sugar, Total Cholesterol, HDL, LDL, Triglycerides as Mean \pm Standard Deviation and compared across the two groups using unpaired ' $t$ ' test and it shows that there is no statistically significant difference between these two groups in the beginning of the study. After three months and six months of intervention all the parameters are studied and repeated measurement ANOVA (Analysis of Variances) is applied to test the significance. 
Table 1a: Demographic and other study parameters of study participants.

\begin{tabular}{|c|c|c|c|c|c|}
\hline & & \multicolumn{4}{|l|}{ Groups } \\
\hline & & $\begin{array}{l}\text { Myoinositol } \\
(\mathbf{n}=70)\end{array}$ & $\begin{array}{l}\text { Combined myoinositol and } \\
\text { D-chiroinositol }(n=70)\end{array}$ & Total & Sig. \\
\hline \multirow{2}{*}{ BMI1(BMI at the starting) } & Mean & 29.710 & 30.029 & 29.869 & 0.524 \\
\hline & Std. Deviation & 3.0692 & 2.8206 & 2.9413 & \\
\hline \multirow{2}{*}{ BMI2 (BMI at 3 months) } & Mean & 29.580 & 28.306 & 28.943 & 0.040 \\
\hline & Std. Deviation & 3.2879 & 2.7750 & 3.0980 & \\
\hline \multirow{2}{*}{ BMI3 (BMI at 6 months) } & Mean & 29.483 & 27.487 & 28.485 & 0.000 \\
\hline & Std. Deviation & 3.3528 & 2.6614 & 3.1779 & \\
\hline \multirow{2}{*}{$\begin{array}{l}\text { WH1 (waist hip ratio at te } \\
\text { starting) }\end{array}$} & Mean & .8827 & 0.8836 & .8831 & 0.797 \\
\hline & Std. Deviation & .02092 & 0.01834 & .01960 & \\
\hline \multirow{2}{*}{$\begin{array}{l}\text { WH2 (waist hip ratio at } 3 \\
\text { monts) }\end{array}$} & Mean & .8799 & 0.8636 & .8717 & 0.049 \\
\hline & Std. Deviation & .02210 & 0.01737 & .02142 & \\
\hline \multirow{2}{*}{$\begin{array}{l}\text { WH3 (waist hip ratio at } 6 \\
\text { months) }\end{array}$} & Mean & .8796 & 0.8454 & .8625 & 0.000 \\
\hline & Std. Deviation & .02039 & 0.02250 & .02741 & \\
\hline \multirow{2}{*}{$\begin{array}{l}\text { SBP1 (systolic blood } \\
\text { pressure at the starting) }\end{array}$} & Mean & 120.64 & 125.54 & 123.09 & 0.055 \\
\hline & Std. Deviation & 15.715 & 9.029 & 13.004 & \\
\hline \multirow{2}{*}{$\begin{array}{l}\text { SBP2 (systolic blood } \\
\text { pressure at } 3 \text { months) }\end{array}$} & Mean & 123.00 & 123.23 & 123.11 & 0.200 \\
\hline & Std. Deviation & 16.003 & 8.391 & 12.731 & \\
\hline \multirow{2}{*}{$\begin{array}{l}\text { SBP3 (systolic blood } \\
\text { pressure at } 6 \text { months) }\end{array}$} & Mean & 119.46 & 118.51 & 118.99 & 0.265 \\
\hline & Std. Deviation & 11.607 & 8.897 & 10.314 & \\
\hline \multirow{2}{*}{$\begin{array}{l}\text { DBP1 (diastolic blood } \\
\text { pressure at the starting) }\end{array}$} & Mean & 78.41 & 81.06 & 79.74 & 0.059 \\
\hline & Std. Deviation & 6.717 & 4.919 & 6.014 & \\
\hline \multirow{2}{*}{$\begin{array}{l}\text { DBP2 (diastolic blood } \\
\text { pressure at } 3 \text { months) }\end{array}$} & Mean & 78.83 & 77.09 & 77.96 & 0.015 \\
\hline & Std. Deviation & 6.806 & 4.989 & 6.009 & \\
\hline \multirow{2}{*}{$\begin{array}{l}\text { DBP3 (diastolic blood } \\
\text { pressure at } 6 \text { months) }\end{array}$} & Mean & 78.57 & 72.86 & 75.71 & 0.024 \\
\hline & Std. Deviation & 6.613 & 5.023 & 6.515 & \\
\hline \multirow{2}{*}{$\begin{array}{l}\text { SFU1 (serum fasting } \\
\text { insulin at the starting) }\end{array}$} & Mean & 18.40 & 18.46 & 18.43 & 0.866 \\
\hline & Std. Deviation & 1.929 & 2.076 & 1.997 & \\
\hline \multirow{2}{*}{$\begin{array}{l}\text { SFU2 (serum fasting } \\
\text { insulin at } 3 \text { months) }\end{array}$} & Mean & 17.79 & 17.87 & 17.83 & 0.690 \\
\hline & Std. Deviation & 2.049 & 1.941 & 1.989 & \\
\hline \multirow{2}{*}{$\begin{array}{l}\text { SFU3 (serum fasting } \\
\text { insulin at } 6 \text { months) }\end{array}$} & Mean & 17.74 & 17.81 & 17.78 & 0.721 \\
\hline & Std. Deviation & 1.674 & 1.883 & 1.775 & \\
\hline \multirow{2}{*}{$\begin{array}{l}\text { FBS1 (fasting Blood } \\
\text { Sugar at the starting) }\end{array}$} & Mean & 96.70 & 96.60 & 96.65 & 0.945 \\
\hline & Std. Deviation & 8.037 & 9.158 & 8.585 & \\
\hline \multirow{2}{*}{$\begin{array}{l}\text { FBS2 (fasting Blood } \\
\text { Sugar at } 3 \text { months) }\end{array}$} & Mean & 96.97 & 93.41 & 95.19 & 0.021 \\
\hline & Std. Deviation & 8.460 & 8.674 & 8.721 & \\
\hline \multirow{2}{*}{$\begin{array}{l}\text { FBS3 (fasting Blood } \\
\text { Sugar at } 6 \text { months) }\end{array}$} & Mean & 96.79 & 90.93 & 93.86 & 0.027 \\
\hline & Std. Deviation & 8.477 & 8.650 & 9.025 & \\
\hline TC1 (Total cholesterol at & Mean & 187.20 & 184.57 & 185.89 & 0.488 \\
\hline the starting) & Std. Deviation & 25.005 & 19.348 & 22.315 & \\
\hline TC2 (Total cholesterol at & Mean & 185.96 & 183.46 & 184.71 & 0.430 \\
\hline 3 months) & Std. Deviation & 24.789 & 19.216 & 22.134 & \\
\hline TC3 (Total cholesterol at & Mean & 185.60 & 182.71 & 184.16 & 0.475 \\
\hline 6 months) & Std. Deviation & 24.677 & 19.139 & 22.050 & \\
\hline HDL1 (serum HDL at the & Mean & 49.30 & 49.59 & 49.44 & 0.806 \\
\hline starting) & Std. Deviation & 7.020 & 6.745 & 6.861 & \\
\hline HDL2 (serum HDL at 3 & Mean & 50.363 & 53.046 & 51.704 & 0.012 \\
\hline months) & Std. Deviation & 7.2907 & 6.5240 & 7.0233 & \\
\hline HDL3 (serum HDL at 6 & Mean & 52.290 & 57.017 & 54.654 & 0.029 \\
\hline months) & Std. Deviation & 7.3304 & 6.7335 & 7.4032 & \\
\hline LDL1 (serum LDL at the & Mean & 125.460 & 130.766 & 128.113 & 0.058 \\
\hline starting) & Std. Deviation & 15.8881 & 15.5403 & 15.8833 & \\
\hline LDL2 (serum LDL at 3 & Mean & 125.704 & 125.784 & 125.744 & 0.013 \\
\hline months) & Std. Deviation & 15.8989 & 15.1120 & 15.4546 & \\
\hline
\end{tabular}


Table 1b: Demographic and other study parameters of study participants.

\begin{tabular}{|c|c|c|c|c|c|}
\hline & & \multicolumn{4}{|l|}{ Groups } \\
\hline & & $\begin{array}{l}\text { Myoinositol } \\
(\mathbf{n}=70)\end{array}$ & $\begin{array}{l}\text { Combined myoinositol and } \\
\text { D-chiroinositol }(n=70)\end{array}$ & Total & Sig. \\
\hline \multirow{2}{*}{$\begin{array}{l}\text { LDL3 } \\
\text { (serum LDL at } 6 \text { months) }\end{array}$} & Mean & 125.539 & 135.871 & 130.705 & 0.329 \\
\hline & Std. Deviation & 15.9789 & 119.1797 & 84.8790 & \\
\hline \multirow{2}{*}{$\begin{array}{l}\text { TG1 } \\
\text { (serum triglycerides at the } \\
\text { starting) }\end{array}$} & Mean & 165.46 & 171.07 & 168.26 & 0.112 \\
\hline & Std. Deviation & 20.989 & 20.596 & 20.909 & \\
\hline \multirow{2}{*}{$\begin{array}{l}\text { TG2 (serum triglycerides } \\
\text { at } 3 \text { months) }\end{array}$} & Mean & 168.34 & 174.14 & 171.24 & 0.150 \\
\hline & Std. Deviation & 21.138 & 20.652 & 21.023 & \\
\hline \multirow{2}{*}{$\begin{array}{l}\text { TG3 (serum triglycerides } \\
\text { at } 6 \text { months) }\end{array}$} & Mean & 165.31 & 171.27 & 168.29 & 0.102 \\
\hline & Std. Deviation & 20.910 & 20.635 & 20.913 & \\
\hline
\end{tabular}

An alpha level of 5\% has been taken, i.e. if any ' $p$ ' value was less than 0.05 , it has been considered as significant. The power of our study was $90 \%$. Coming to the analysis, age and other parameters are studied as baseline evaluation (pre-intervention) and statistical tests applied to test the presence of any significance. It was found that there was no statistically significant difference between these two groups.

At the end of three months and six months the measurements were again studied and it was found that those datas were normally distributed and no statistically significant difference present between these two groups. At the end of 3 months BMI, WH Ratio, Diastollic BP, FBS, LDL were found to be reduced significantly and HDL was increased significantly in combined therapy group than myo-inositol only group. Other values of other parameters were unrewarding.

At the end of 6 months in the combined therapy group all of the above-mentioned parameters except LDL in which statistically significant changes noted were again found to carry statistically significant difference from the myoinositol group.

\section{DISCUSSION}

Carlomagno $G$ et al and Heimark D et al in two separate studies from two independent laboratories have reported a significant reduction of (Myo-inositol/D-chiro-inositol) ratio in D-chiro-inositol from 100:1 in healthy women to 0.2:1 in PCOS patients. ${ }^{12,13}$ Those studies suggest marked MI depletion and an increased DCI reduction indicating the need of their supplementation in PCOS patients.

A trial was conducted by Nordio $\mathrm{M}$ and Proietti E on fifty patients where the metabolic effect and pre-determined parameters were assessed between two groups; one group treated with combined (Myo-inositol and D-chiroinositol) and the second group was given myo-inositol only. ${ }^{14}$ The study showed that combined therapy is effective in reducing diastolic blood pressure and serum sex hormones significantly. It also showed that plasma glucose and insulin sensitivity index measurements were more controlled at the end of 3 months with combined therapy than myo-inositol only.

A study conducted by Mnozzi M et al on Cardio-vascular risk factor of PCOS patients by giving [Myo-inositol (550 $\mathrm{mg})+$ D-chiro-inositol (13.8 mg)] (MI+DCI) twice daily for six months. ${ }^{15}$ Statistical analysis shows statistically significant reduction in serum fasting insulin, fasting blood sugar, LDL and statistically significant increase in HDL level.

In present study, at the end of 3 months BMI, WH Ratio, Diastollic BP, FBS, LDL were found to be reduced significantly and HDL was increased significantly in combined therapy group than myo-inositol only group. At the end of 6 months in the combined therapy group all of the above-mentioned parameters except LDL have shown statistically significant changes.

\section{CONCLUSION}

Considering the wide range of presenting signs and symptoms of PCOS, early diagnosis and treatment, not only to control gynaecological problems but also to prevent and treat metabolic complications, is necessary. Combined (Myo-inositol+D-chiro-inositol) therapy proved to be more efficacious than Myo-inositol only in reducing individual components of metabolic syndrome. Dietary habits and physical exercise of individual may play some role which has not been confounded.

Funding: No funding sources

Conflict of interest: None declared

Ethical approval: The study was approved by the Institutional Ethics Committee

\section{REFERENCES}

1. Genazzani AD, Battaglia C, Malavasi B, Strucchi C, Tortolani F, Gamba O. Metformin administration modulates and restores luteinizing hormone 
spontaneous episodic secretion and ovarian function in nonobese patients with polycystic ovary syndrome. Fertil Steril. 2004;81(1):114-9.

2. Rotterdam ESHRE/ASRM-Sponsored PCOS Consensus Workshop Group. Revised 2003 consensus on diagnostic criteria and long term health risks related to polycystic ovary syndrome. Fertil Steril. 2004;81(1):19-25.

3. Azziz RJ. Controversy in clinical endocrinology: diagnosis of polycystic ovarian syndrome: the Rotterdam criteria are premature. Clin Endocrinol Metab. 2006;91(3):781-5.

4. Azziz R, Carmina E, Dewailly D, DiamantiKandarakis E, Escobar-Morreale HF, Futterweit W, et al. Positions statement: criteria for defining polycystic ovary syndrome as a predominantly hyperandrogenic syndrome: an Androgen Excess Society guideline. J Clin Endocrinol Metab. 2006;91(11):4237-45.

5. 5. Azziz R, Carmina E, Dewailly D, DiamantiKandarakis E, Escobar-Morreale HF, Futterweit W, et al. The Androgen Excess and PCOS Society criteria for the polycystic ovary syndrome: the complete task force report. Fertil Steril. 2009;91(2):456-88.

6. Expert panel on detection, evaluation, and treatment of high blood cholesterol in adults: Executive Summary of the Third Report of the National Cholesterol Education Program (NCEP) expert panel on detection, evaluation, and treatment of high blood cholesterol in adults (Adult Treatment Panel III). JAMA 2001;285:2486-97.

7. Vause TD, Cheung AP, Sierra S, Claman P, Graham J, Guillemin JA et al. Ovulation induction in polycystic ovary syndrome. J Obstet Gynaecol Can. 2010;32(5):495-502.

8. Lisi F, Carfagna P, Oliva MM, Rago R, Lisi R, Poverini $\mathrm{R}$ et al. Pretreatment with myo-inositol in non-polycystic ovary syndrome patients undergoing multiple follicular stimulation for IVF: a pilot study. Reprod Biol Endocrinol. 2012;10:52.

9. Legro RS, Arslanian SA, Ehrmann DA, Hoeger KM, Murad MH, Pasquali $\mathrm{R}$ et al. Diagnosis and
Treatment of Polycystic Ovary Syndrome: An Endocrine Society Clinical Practice Guideline. J Clini Endocrinol Metab. 2013;98(12):2013-2350.

10. Balkau B, Charles MA. Comment on the provisional report from the WHO consultation. European Group for the Study of Insulin Resistance (EGIR) (Letter). Diabet Med. 1999;16:442-3.

11. Iuorno MJ, Jakubowicz DJ, Baillargeon JP, Dillon P, Gunn RD, Allan G et al. Effects of D-chiroinositol in lean women with the polycystic ovary syndrome. Endocr Pract. 2002;8:417-23.

12. Heimark D, McAllister J, Larner J. Decreased Myoinositol to chiro-inositol $(\mathrm{m} / \mathrm{c})$ ratios and increased $\mathrm{m} / \mathrm{c}$ epimerase activity in PCOS theca cells demonstrate increased insulin sensitivity compared to controls. Endocr J. 2014;61(2):111-7.

13. Unfer V, Carlomagno G, Papaleo E, Vailati S, Candiani M, Baillargeon JP. Hyperinsulinaemia alters myo-inositol to d-chiro-inositol ratio in the follicular fluid of PCOS patients. Reprod Sci. 2014;21(7):854-58.

14. Minozzi M, Nordio M, Pajalich R.. The combined therapy myo-inositol plus d-chiro-inositol, in a physiological ratio, reduces the cardio-vascular risk by improving the lipid profile in PCOS patients. Eur Rev Med Pharmacol Sci. 2013;17:537-40.

15. Nordio M, Proietti E. The Combined therapy myoinositol and d-chiro-inositol reduces the risk of metabolic disease in PCOS overweight patients compared to myo-inositol alone. Eur Rev Med Pharmacol Sci. 2012;16:575-81.

Cite this article as: Pande M, Seal A, Mishra S, Dasgupta A, Sengupta M, Dastider R. The effects of combined therapy of myo-inositol and D-chiro inositol in reduction of the individual components of metabolic syndrome in overweight PCOS patients compared to myo-inositol supplementation alone: a prospective randomised controlled trial. Int J Reprod Contracept Obstet Gynecol 2017;6:2939-43. 